\title{
INFLUENCIA DEL EXPLANTE Y MEDIO DE CULTIVO EN LA EMBRIOGÉNESIS SOMÁTICA EN HOJAS DE CAFÉ
}

\author{
INFLUENCE OF EXPLANT AND CULTURE MEDIUM ON SOMATIC \\ EMBRYOGENESIS OF COFFEE LEAVES
}

\author{
Pablo López-Gómez ${ }^{1}$, Leobardo Iracheta-Donjuan ${ }^{{ }^{*}}$, Marbella Castellanos-Juárez ${ }^{1}$, \\ Ismael Méndez-López ${ }^{1}$, Alfredo Sandoval-Esquivez ${ }^{1}$, Juan F. Aguirre-Medina ${ }^{1}$, \\ Ma. Carmen Ojeda-Zacarías ${ }^{2}$ y Adriana Gutiérrez-Díez ${ }^{2}$
}

${ }^{1}$ Campo Experimental Rosario Izapa, Instituto Nacional de Investigaciones Forestales, Agrícolas y Pecuarias. 30870, Tuxtla Chico, Chiapas. México. Tel. 01 (962) 1100271. ${ }^{2}$ Facultad de Agronomía, Universidad Autónoma de Nuevo León. Carretera Zuazua-Marín km. 17.5. 66700, Marín, N.L., México.

* Autor para correspondencia (iracheta.leobardo@inifap.gob.mx)

\section{RESUMEN}

La inducción de la embriogénesis somática en café (Coffea spp.) es afectada por el tipo de explante y el medio de cultivo. Este trabajo se efectuó para obtener el tipo de explante foliar y el medio de cultivo óptimos para la inducción de la embriogénesis somática en 13 genotipos mejorados de Coffea spp. Se establecieron explantes de hojas inmaduras $(\mathrm{H} i)$, jóvenes $(\mathrm{HJ})$ y maduras $(\mathrm{Hm})$ de cada genotipo. Posteriormente, se evaluaron sólo explantes de $\mathrm{Hj}$ y $\mathrm{Hi}$ en tres medios de cultivo: el medio testigo MT con BAP $\left(1.12 \mathrm{mg} \mathrm{L}^{-1}\right)$; el medio MS1 con BAP $\left(1.12 \mathrm{mg} \mathrm{L}^{-1}\right)$ y 2,4-D $\left(0.05 \mathrm{mg} \mathrm{L}^{-1}\right)$; y el medio MS2 con BAP (2.21 $\left.\mathrm{mg} \mathrm{L}^{-1}\right), 2,4-D\left(0.05 \mathrm{mg} \mathrm{L}^{-1}\right)$, AIB $(1 \mathrm{mg}$ $\left.\mathrm{L}^{-1}\right)$ y Benomyl $\left(1 \mathrm{~g} \mathrm{~L}^{-1}\right)$. Se evaluó la oxidación, contaminación, crecimiento del borde del explante, callogénesis, callo embriogénico y número de embriones globulares. Las $\mathrm{Hm}$ no demostraron capacidad de respuesta morfogénica. Las $H j$ presentaron porcentajes de 18 a $100 \%$ de callogénesis en cuatro de los genotipos y de 45 a 63 $\%$ en dos genotipos, en tanto que las $\mathrm{Hi}$ formaron de 9 a $100 \%$ de callo en doce genotipos y de 18 a $72 \%$ en nueve genotipos. La presencia de callo en los explantes de $\mathrm{Hi}$ y $\boldsymbol{H} \boldsymbol{j}$ dependió del genotipo y del medio de cultivo empleado. El callo inducido por los diferentes componentes de los medios evaluados no siempre fue embriogénico. El número de embriones globulares dependió del genotipo y este osciló entre 58 a 424 en $0.83 \mathrm{~g}$ de callo, i.e. 70 a 510 embriones $\mathrm{g}^{-1}$. Se indujo la embriogénesis somática en explantes foliares jóvenes e inmaduros, en al menos un tratamiento, y fue posible identificar el tipo de explante y medio de cultivo de mejor respuesta morfogénica en cada genotipo.

Palabras clave: Coffea canephora, C. arabica, callogénesis, embriogénesis.

\section{SUMMARY}

Somatic embryogenesis induction in coffee (Coffea spp.) is affected by explant type and culture medium. This work was done in order to obtain the optimal type of foliar explant and culture medium for somatic embryogenesis induction in 13 selected genotypes of Coffea spp. Explants of immature $(\mathrm{Hi})$, young $(\mathrm{Hy})$ and mature leaves $(\mathrm{Hm})$ were compared in each genotype. Later, only $\mathrm{Hy}$ and $\mathrm{Hi}$ explants were evaluated in three culture media: the control MT medium with BAP (1.12 $\left.\mathrm{mg} \mathrm{L}^{-1}\right)$; the MS1 medium with BAP $\left(1.12 \mathrm{mg} \mathrm{L}^{-1}\right)$ and 2,4-D (0.05 $\left.\mathrm{mg} \mathrm{L}^{-1}\right)$; and MS2 medium with BAP $\left(2.21 \mathrm{mg} \mathrm{L}^{-1}\right), 2,4-$ D $\left(0.05 \mathrm{mg} \mathrm{L}^{-1}\right)$, AIB $\left(1 \mathrm{mg} \mathrm{L}^{-1}\right)$ and Benomyl $\left(1 \mathrm{~g} \mathrm{~L}^{-1}\right)$. The percentages of oxidation, contamination, growth of tissue border, callogenesis, embryogenic callus and number of globular embryos were evaluated. $\mathrm{Hm}$ did not present morphogenic response. $\mathrm{Hy}$ exhibited $18 \%$ to $100 \%$ of callogenesis in four genotypes and $45 \%$ to $63 \%$ in two genotypes; on the other hand, $\mathrm{Hy}$ formed $9 \%$ to 100 $\%$ of callus in 12 genotypes and $18 \%$ to $72 \%$ in nine genotypes. Callus presence in $\mathrm{Hi}$ and $\mathrm{Hy}$ explants depended on the genotype and culture medium. The induced callus by different components of the evaluated medium was not always embryogenic. The number of globular embryos depended on the genotype and oscillated between 58 to 424 embryos in $0.83 \mathrm{~g}$ of callus, i.e. 70 to 510 embryos $^{-1}$. The somatic embryogenesis was induced in young and immature foliar explants, in at least one treatment; and the explant type and culture medium with the best morphogenetic response for each genotype was identified.

Index words: Coffea canephora, C. arabica, callogenesis, embryogenesis.

\section{INTRODUCCIÓN}

Los estudios sobre la propagación asexual mediante la embriogénesis somática en café (Coffea arabica L. y $C$. canephora $\mathrm{P}$.) iniciaron a nivel mundial en la década de los 70's, con los estudios de callogénesis y embriogénesis de Staritsky (1970), Herman y Haas (1975), y Sondahl y Sharpe (1977). Después Ducos et al. (1993), Zamarripa (1994), Naidu y Sreenath (1998), Ducos et al. (1999), Nguyen et al. (1999), Afreen et al. (2002) e Ípeckci y Gözükirmizi (2003), demostraron que era posible el cultivo de células embriogénicas en medio líquido, con reportes de 2000 a 400000 embriones por litro de medio de cultivo, según la especie y el genotipo. 
Al evaluar $C$. canephora, $C$. arabica e híbridos Arabusta, Zamarripa y Pétiard (2004) reportaron un fuerte efecto del genotipo sobre la inducción de la embriogénesis somática. Por tal motivo es frecuente observar que un medio de cultivo induzca distintas respuestas en la inducción de embriogénesis en diversos genotipos (Zamarripa y Pétiard 2004; Cueto et al., 2007).

La concentración o ausencia de algunos componentes en los medios de cultivo, como sales minerales, ciertas citocininas y auxinas, así como el balance entre estos reguladores y otros componentes como antioxidantes o fungicidas, desencadenan respuestas variadas que en muchas ocasiones no son las adecuadas para un proceso de multiplicación masiva eficiente y práctica (Margara 1988; Pido et al., 1995).

El éxito en la diferenciación de callo embriogénico también depende del tipo de explante, de su estado fisiológico, y de la interacción de los microorganismos contaminantes con las fitohormonas. La concentración endógena de estas últimas varía entre tejidos y genotipos, por lo que la interacción con los reguladores presentes en el medio de cultivo propician diversos cambios epigenéticos que van desde ausencia de respuesta morfogénica, presencia de callo friable sin diferenciación de embriones, hasta formación de callos embriogénicos. Ha sido posible inducir embriogénesis somática a partir de diversos explantes, como segmentos de tallo (Staritsky, 1970), hojas (Dublin, 1981; Yasuda et al., 1985), óvulos (Lanaud, 1981) e hipocótilos (Giridhar et al., 2004). En la mayoría de casos la inducción de callo es variable, y sólo en algunos tejidos se logra una mayor proporción de callo embriogénico, caracterizado por la presencia de células isodiamétricas con núcleos grandes; otros tejidos producen mayor cantidad de callo conformado por células parenquimatosas alargadas no embriogénicas. El grado de desarrollo de los explantes como hipocótilos y hojas, puede inducir la formación de la embriogénesis directa (Dublin, 1981; Giridhar et al., 2004), en lugar de callo embriogénico con alto potencial de multiplicación.

Conseguir una metodología específica de regeneración para cada genotipo de interés se hace necesario debido al incremento de la demanda de plantas regeneradas in vitro y al hecho de poder explotar el potencial morfogénico de los genotipos élite de Coffea. La investigación para elevar la eficiencia de regeneración de plantas mediante embriogénesis somática durante la fase de inducción de la callogénesis, podría disminuir los problemas de contaminación, oxidación y la falta de respuesta morfogénica. La presente investigación tuvo como objetivo seleccionar el mejor tipo de explante en 13 genotipos de Coffea spp., en cuanto a su potencial para la inducción de callo embriogénico, así como elevar dicha inducción mediante modificaciones a los medios de cultivo, y así identificar líneas embriogénicas con alta capacidad de regeneración.

\section{MATERIALES Y MÉTODOS}

Este trabajo se realizó en Rosario Izapa, Chiapas ubicado en el Km. 18 de la carretera Tapachula-Cacahoatán, municipio de Tuxtla Chico, Chiapas, México.

\section{Material biológico}

Se usaron diez genotipos de C. canephora, variedad 'Robusta' (INIFAP 95-8, 95-9, 97-10, 97-12, 97-15, 97$18,97-19,97-20,00-24$ y 00-28), y tres líneas 'Catimor F7' de C. arabica (INIFAP 2000-692, 2000-1018 y 20001128). Los genotipos de $C$. arabica fueron elegidos por su alto rendimiento y resistencia a la roya anaranjada de la hoja (Hemileia vastatrix Berk \& Br.), y los de $C$. canephora por su alto rendimiento; todos ellos provenientes del programa de mejoramiento genético del Campo Experimental Rosario Izapa del Instituto Nacional de Investigaciones Forestales Agrícolas y Pecuarias (INIFAP-CERI).

\section{Preparación y desinfección de explantes}

Las plantas madre (de 9 a 11 años de edad) fueron asperjadas diariamente con una solución fungicida $\left(1 \mathrm{~g} \mathrm{~L}^{-1}\right.$ de Amistar ${ }^{\circledR}$ [Azoxystrobin 50 \%]) durante 3 d. Posteriormente se colectaron las hojas y se lavaron con detergente comercial, luego se enjuagaron con agua corriente, y se colocaron en una solución antioxidantefungicida previamente esterilizada $\left(30 \mathrm{~g} \mathrm{~L}^{-1}\right.$ de sacarosa, $100 \mathrm{mg} \mathrm{L}^{-1}$ de ácido ascórbico, $150 \mathrm{mg} \mathrm{L}^{-1}$ de ácido cítrico y $1 \mathrm{~g} \mathrm{~L}^{-1}$ de Amistar $\left.{ }^{\circledR}\right)$. Las hojas en estas condiciones fueron sometidas a vacío parcial con una bomba de vacío (Welch Duo Seal ${ }^{\circledR}$ 1400) por 3 min. Las hojas permanecieron en la solución antioxidante-fungicida por 10 min y luego se sometieron a diferentes procesos de desinfección para cada genotipo.

La desinfección se efectuó en condiciones asépticas y consistió en la inmersión de las hojas en la solución desinfectante a concentraciones adecuadas para cada genotipo, de $1 \%$ (v/v) de $\mathrm{NaClO}$ para los genotipos INIFAP 97-19, 97-12, 2000-1128, 2000-1018, y 2000-692; de 3 $\%$ de $\mathrm{NaClO}$ para $97-10,97-18,97-15,95-8$ y $00-28 ; 3.5$ $\%$ de $\mathrm{Ca}(\mathrm{ClO})_{2}$ para 00-24 y $97-20$; y $7 \%$ de $\mathrm{Ca}(\mathrm{ClO})_{2}$ para el genotipo 95-9; estos tratamientos permiten bajos niveles de oxidación y contaminación $(<10 \%)$. Luego las hojas se enjuagaron con agua destilada esterilizada y se colocaron en la solución antioxidante antes señalada, durante el proceso de su disección. 


\section{Tipo de explante foliar}

Se establecieron explantes de $1 \mathrm{~cm}^{2}$ provenientes de hojas inmaduras de tres meses de edad de color amarillo cobre, correspondiente al primer par de hojas expandidas en sentido basípeto a partir de hijuelos de 10 meses provenientes de plantas crecidas en campo de 9 a 11 años; hojas jóvenes de color verde claro (cercana a madurez), provenientes del cuarto par de hojas en sentido basípeto; y hojas maduras de color verde oscuro que correspondieron al sexto par en sentido basípeto; estos dos últimos provenientes de ramas plagiotrópicas de las mismas plantas. Se eligieron hojas planas (sin ondulaciones en los bordes) y sin daños físicos ni manifestaciones de enfermedades.

Los explantes desinfectados se colocaron asépticamente en tubos de ensayo de $16 \times 150 \mathrm{~mm}$ con $20 \mathrm{~mL}$ de medio de cultivo esterilizado. Los tres tipos de explantes de cada genotipo conformaron tres tratamientos, y de cada uno hubo 11 repeticiones, donde un explante constituyó una repetición. Los explantes se incubaron en oscuridad total a $26{ }^{\circ} \mathrm{C}$ y $50 \%$ de humedad relativa.

El medio de cultivo usado en este experimento estuvo compuesto por las sales inorgánicas de Yasuda et al. (1985), adicionado con las vitaminas descritas por Gamborg (2002), con $30 \mathrm{~g} \mathrm{~L}^{-1}$ de sacarosa, $1.12 \mathrm{mg} \mathrm{L}^{-1}$ de bencilaminopurina (BAP) y $5 \mathrm{~g} \mathrm{~L}^{-1}$ de Phytagel Sigma ${ }^{\circledR}$, y pH de 5.8 ajustado con $\mathrm{KOH}$ o $\mathrm{HCl} 1 \mathrm{~N}$. El medio de cultivo se esterilizó en autoclave a $121{ }^{\circ} \mathrm{C}$ y 1.1 $\mathrm{kg} \mathrm{cm}^{-2}$ de presión durante $20 \mathrm{~min}$.

Las variables de respuesta fueron: nivel de oxidación del tejido dañado, con la escala de $0,25,50,75$ y $100 \%$ del explante necrosado; porcentaje de contaminación por hongos o bacterias; porcentaje de callogénesis, por presencia de callo en el explante; y porcentaje de callo embriogénico, que se evaluó por la formación de embriones somáticos en fase globular. Las variables de oxidación, contaminación y callogénesis fueron medidas a los $30 \mathrm{~d}$ del establecimiento in vitro, y el porcentaje de callo embriogénico a los $60 \mathrm{~d}$.

\section{Medio de cultivo para inducir callogénesis}

Se establecieron explantes de $1 \mathrm{~cm}^{2}$ provenientes de hojas inmaduras y jóvenes de los 13 genotipos élite de café en tres medios de cultivo. El primer medio correspondió al testigo (MT), y estuvo compuesto por las sales inorgánicas de Yasuda et al. (1985), más las vitaminas de Gamborg (2002), $30 \mathrm{~g} \mathrm{~L}^{-1}$ de sacarosa, 1.12 $\mathrm{mg} \mathrm{L}^{-1}$ de BAP y $5 \mathrm{~g} \mathrm{~L}^{-1}$ de Phytagel Sigma ${ }^{\circledR}$, y con $\mathrm{pH}$ ajustado a 5.8. El segundo medio (MS1) estuvo compuesto por las sales inorgánicas de Murashige y
Skoog (1962), más las vitaminas de Gamborg (2002), 30 $\mathrm{g} \mathrm{L}^{-1}$ de sacarosa, $1.12 \mathrm{mg} \mathrm{L}^{-1}$ de BAP, $0.5 \mathrm{mg} \mathrm{L}^{-1} \mathrm{de}$ ácido 2,4-diclorofenoxiacético (2, 4-D) y $5 \mathrm{~g} \mathrm{~L}^{-1}$ de Phytagel Sigma ${ }^{\circledR}$, con pH ajustado a 6.3. El tercer medio (MS2) estuvo compuesto por las sales de Murashige y Skoog (1962) diluidas a $50 \%$, más las vitaminas descritas por Gamborg (2002), $30 \mathrm{~g} \mathrm{~L}^{-1}$ de sacarosa, $2.21 \mathrm{mg} \mathrm{L}^{-1} \mathrm{de}$ BAP, $0.5 \mathrm{mg} \mathrm{L}^{-1}$ de $2,4-\mathrm{D}, 1 \mathrm{mg} \mathrm{L}^{-1}$ de ácido indolbutírico (AIB), $1 \mathrm{~g} \mathrm{~L}^{-1}$ del fungicida Benomyl ${ }^{\circledR} 50 \%, 100 \mathrm{mg}$ $\mathrm{L}^{-1}$ de caseína hidrolizada, $1 \mathrm{mg} \mathrm{L}^{-1}$ de glicina, $400 \mathrm{mg} \mathrm{L}^{-1}$ de extracto de malta y $2 \mathrm{~g} \mathrm{~L}^{-1}$ de Phytagel Sigma ${ }^{\circledR}$, y con $\mathrm{pH}$ ajustado a 5.6. Cada medio fue ajustado al $\mathrm{pH}$ indicado con $\mathrm{KOH}$ o $\mathrm{HCl} 1 \mathrm{~N}$, y esterilizado en autoclave a 121 ${ }^{\circ} \mathrm{C}$ y $1.1 \mathrm{~kg} \mathrm{~cm}^{-2}$ de presión durante $20 \mathrm{~min}$.

Los explantes se colocaron en cajas Petri de 12 x 100 $\mathrm{mm}$ con $20 \mathrm{~mL}$ de medio de cultivo esterilizado. Se aplicaron así seis tratamientos a cada genotipo, resultado de la combinación de los dos tipos de explantes y los tres medios de cultivo. Cada tratamiento tuvo quince repeticiones, y un explante representó una repetición. Los explantes se incubaron en oscuridad total a $26{ }^{\circ} \mathrm{C}$ y $50 \%$ de humedad relativa. Las variables de respuesta para este experimento fueron: porcentaje de explantes con capacidad de respuesta morfogénica, expresada en crecimiento de los bordes del explante; porcentaje de explantes con callogénesis; y porcentaje de explantes con callo embriogénico, esta última detectada con base en la presencia de embriones en diferentes estados de desarrollo (fase globular, acorazonado, torpedo y cotiledonar), en una muestra de $0.83 \mathrm{~g}$ de callo. La evaluación de las variables se llevó a cabo a los $60 \mathrm{~d}$ del establecimiento in vitro.

En ambos experimentos se utilizó un diseño completamente al azar. El análisis de varianza de los datos previamente transformados con $\sqrt{X+1}$, se hizo mediante el paquete estadístico SAS versión 6.12 (SAS Institute, 1997) y para la comparación de medias se utilizó la prueba de Tukey con un nivel de $1 \%$ de significancia estadística.

\section{RESULTADOS Y DISCUSIÓN}

\section{Tipo de explante foliar e inducción de callogénesis}

Después del establecimiento in vitro se presentaron problemas de contaminación y oxidación, y a los $30 \mathrm{~d}$ de la siembra solamente los genotipos INIFAP 00-24, 95-8, 97-18, 97-19, 97-20 y 2000-692 no mostraron contaminación en al menos uno de sus tratamientos (Cuadro 1). Los explantes provenientes de hoja joven y de hoja inmadura de INIFAP 95-8, 97-10, 97-15 y 97-20 fueron los que presentaron menor nivel de contaminación a los 30 d, con valores de cero a $54 \%$; en los demás genotipos solamente 
los explantes provenientes de hoja inmadura presentaron menores niveles de contaminación, con valores de 0 a 36 $\%$. Con los explantes provenientes de hoja madura se presentaron altos porcentajes de contaminación, desde 90 hasta $100 \%$ en todos los genotipos, lo cual puede atribuirse a que estas hojas presentan mayor cantidad de unidades formadoras de colonias de microorganismos, además que el crecimiento de su pared celular y la formación de ceras y ligninas epicuticulares es mayor que en hojas jóvenes, lo que dificulta la acción del agente desinfectante en los microorganismos endógenos (Hartmann y Kester, 1998). Según Lallana et al. (2006), la escasa capacidad de absorción de sustancias por parte de tejidos maduros, se debe a los depósitos de cera de mayor grosor presentes en la cutícula foliar.

La mayoría de explantes presentaron valores de oxidación mayores a $50 \%$, excepto en los genotipos INIFAP 00-24, 95-8, 95-9 y 97-20 que tuvieron porcentajes inferiores a $45 \%$ en explantes de hoja inmadura o joven (Cuadro 1). En ocho genotipos del INIFAP (INIFAP 00-24, 95-8, 95-9, 97-10, 97-12, 97-15, 97-20 y 2000-1128), los explantes provenientes de hoja inmadura de cinco genotipos (INIFAP 00-24, 95-9, 97-12, 97-18 y 2000-1128) tuvieron menor nivel de oxidación (2 a $60 \%$ ) que el resto de los genotipos, principalmente en los explantes provenientes de hoja madura que tuvieron altos porcentajes de oxidación (60 a $100 \%$ ). Según Jha y Das (2004), la respuesta diferencial entre genotipos se debe al control genético; en Oryza sativa un único gen regula el oscurecimiento del explante (Zhong et al., 2007), mientras que en Arabidopsis se estiman cerca de 152 genes en el control del nivel de sustancias reactivas al oxígeno (Mittler et al., 2004). La respuesta en los explantes de hoja madura se puede atribuir a su alto contenido de fenoles y polifenoles, ya que éstos son muy comunes en el metabolismo del oxígeno y son sustancias reactivas a este último (Sánchez-Cuevas y Salaverría, 2004; Velázquez et al., 2004). Al respecto, George (1996) indica que los tejidos juveniles son menos propensos a problemas de oxidación que los tejidos maduros, aunque en Saccharum spp. el cultivo de tejidos inmaduros presentó más problemas de oxidación que tejidos más desarrollados (Aftab e Iqbal, 1999).

Hubo formación de callo en la mayoría de genotipos, en al menos uno de sus tratamientos, con excepción del genotipo INIFAP 00-28, con porcentajes de callogénesis que fluctuaron de 9 a $100 \%$, aunque éstos no siempre fueron del tipo embriogénico. A los $30 \mathrm{~d}$ se detectaron diferencias $(\mathrm{P} \leq 0.01)$ en diez genotipos en cuanto a formación de callo (Cuadro 1) en explantes provenientes de hoja inmadura y joven con valores de 36 a $100 \%$ de callogénesis, y en nueve de ellos (INIFAP 97-19, 2000-
$1128,97-12,97-10,97-18,95-8,97-15,00-24$ у 95-9) los explantes provenientes de hojas inmaduras fueron mejores en formación de callo (50 a $100 \%)$. El resto de genotipos (INIFAP 00-28, 2000-692 y 2000-1018) presentó de 0 a $9 \%$ de callogénesis. Al estudiar clones de C. canephora P. var 'Robusta', González et al. (2001) encontraron desde clones recalcitrantes hasta clones muy reactivos, que atribuyeron a la existencia de controles genéticos del comportamiento in vitro de los explantes.

Los explantes provenientes de hoja madura no presentaron capacidad alguna para la formación de callo a los $30 \mathrm{~d}$ de la siembra (Cuadro 1). Al respecto, Jensen et al. (1998) indican que los órganos jóvenes tienen mejor respuesta al establecimiento in vitro que los obtenidos de materiales adultos, es decir, entre más joven y menos diferenciado sea un tejido, más fácil será su adaptación y respuesta al cultivo in vitro.

La inducción de la embriogénesis somática, evaluada mediante la formación de callo embriogénico a los 60 d de la siembra, presentó diferencias $(\mathrm{P} \leq 0.01)$ entre tipos de explante (Cuadro 1). Los genotipos INIFAP 00-24, 958, 95-9, 97-10, 97-12, 97-15, 97-19 y 97-20 formaron callo embriogénico en al menos uno de sus tratamientos, con porcentajes de 18 a $72 \%$. Tres genotipos de $C$. arabica (INIFAP 2000-692, 2000-1018 y 2000-1128) y uno de $C$. canephora (INIFAP 00-28) fueron los únicos incapaces de generar callo embriogénico en todos los tipos de explante. En seis genotipos (INIFAP 95-8, 95-9, 97-12, 97-15, 97-18 y 97-19), los explantes provenientes de hojas jóvenes e inmaduras dieron la más alta formación de callo embriogénico (27 a $73 \%)$; los explantes provenientes de hojas inmaduras de cinco genotipos (INIFAP 95-8, 95-9, 97-15, 97-18 y 97-19) constituyen la mejor alternativa para la formación de callo embriogénico, mientras que el resto de genotipos presentaron bajos porcentajes de callo embriogénico (0 a $45 \%)$.

Los explantes con capacidad de formar embriones somáticos expresaron tal capacidad días después que aquéllos que sólo pudieron formar células callosas, porque el callo embriogénico crece más lento que el callo no embriogénico (González et al., 2002).

Así, los explantes de hojas inmaduras y jóvenes fueron los mejores para la inducción de callogénesis, incluso para la formación de callo embriogénico. Sin embargo, es necesario mejorar el medio de cultivo para aumentar el porcentaje de explantes embriogénicos. Los genotipos que no tuvieron capacidad de respuesta (INIFAP 2000-1128, 2000-692, 2000-1018, 00-28), son indicativos de la necesidad de llevar a cabo estudios adicionales en otros medios de cultivo. 


\section{Medio de cultivo y callogénesis}

Se detectaron diferencias $(\mathrm{P} \leq 0.01)$ entre genotipos para las variables explantes con crecimiento de bordes y callogénesis. En la mayoría de genotipos hubo crecimiento en los bordes de magnitud mayor de $48 \%$, con excepción de los genotipos INIFAP 00-24, 97-10, 20001018 y 2000-1128 que dieron porcentajes menores. En la variable callogénesis la respuesta fue similar, ya que la mayoría de genotipos presentó niveles altos de callogénesis (más de $47 \%$ ), con excepción de los genotipos INIFAP 00-24, 97-10, 2000-1018 y 2000-1128 (Cuadro 2). En formación de callo embriogénico los genotipos INIFAP 95-8 y 00-28, tuvieron valores de 77 a $97 \%$, y superaron $(\mathrm{P} \leq 0.01)$ al resto de los materiales cuyos valores fluctuaron de 2 a $41 \%$ de callo embriogénico.

En crecimiento no se detectaron diferencias entre los medios empleados, pero éstos sí afectaron la callogénesis. El medio MS2 fue el que indujo el porcentaje más bajo (38 \%) de callo. Boxtel y Berthouly (1996), al inducir callogénesis en clones de $C$. canephora y $C$. arabica en un medio de cultivo semejante, pero con 2-iP además de BAP, también observaron baja frecuencia de callogénesis. El medio MT indujo el mayor porcentaje de callo embriogénico con $41 \%$ (Figura 1), similar al obtenido por Yasuda et al. (1985) que en C. arabica lograron producir callo friable y embriones somáticos sólo con la presencia del BAP $(5 \mu \mathrm{M})$ como regulador.

Cuadro 1. Porcentajes de contaminación, oxidación y callogénesis en tres tipos de explantes foliares a los $30 \mathrm{~d}$ del establecimiento in vitro, y porcentaje de callo embriogénico a los $60 \mathrm{~d}$.

\begin{tabular}{|c|c|c|c|c|c|c|c|c|c|}
\hline \multirow[t]{2}{*}{ Genotipo INIFAP } & \multirow{2}{*}{$\begin{array}{l}\text { Tipo de hoja } \\
\text { Madura }\end{array}$} & \multicolumn{2}{|c|}{ Contaminación (\%) } & \multicolumn{2}{|c|}{ Oxidación (\%) } & \multicolumn{2}{|c|}{ Callogénesis (\%) } & \multicolumn{2}{|c|}{ Callo embriogénico (\%) } \\
\hline & & 100.0 & $\mathrm{a}^{\dagger}$ & 100.0 & $\mathrm{a}$ & 0.0 & $\mathrm{~b}$ & 0.0 & $\mathrm{~b}$ \\
\hline \multirow[t]{3}{*}{$97-19$} & Joven & 100.0 & $\mathrm{a}$ & 100.0 & $\mathrm{a}$ & 0.0 & $\mathrm{~b}$ & 0.0 & $\mathrm{~b}$ \\
\hline & Inmadura & 0.0 & $\mathrm{~b}$ & 77.2 & $\mathrm{a}$ & 100.0 & $\mathrm{a}$ & 63.6 & $\mathrm{a}$ \\
\hline & Madura & 81.8 & a & 100.0 & $\mathrm{a}$ & 0.0 & $\mathrm{~b}$ & 0.0 & $\mathrm{a}$ \\
\hline \multirow{3}{*}{$2000-11288^{\dagger \dagger}$} & Joven & 100.0 & $\mathrm{a}$ & 100.0 & $\mathrm{a}$ & 0.0 & $\mathrm{~b}$ & 0.0 & $\mathrm{a}$ \\
\hline & Inmadura & 27.3 & $\mathrm{~b}$ & 59.1 & $\mathrm{~b}$ & 54.5 & a & 0.0 & a \\
\hline & Madura & 100.0 & a & 100.0 & $\mathrm{a}$ & 0.0 & $\mathrm{~b}$ & 0.0 & $\mathrm{~b}$ \\
\hline \multirow[t]{3}{*}{$97-12$} & Joven & 100.0 & $\mathrm{a}$ & 100.0 & $\mathrm{a}$ & 0.0 & $\mathrm{~b}$ & 0.0 & $\mathrm{~b}$ \\
\hline & Inmadura & 36.4 & $\mathrm{~b}$ & 50.0 & $\mathrm{~b}$ & 63.6 & $\mathrm{a}$ & 27.2 & $\mathrm{a}$ \\
\hline & Madura & 100.0 & $\mathrm{a}$ & 100.0 & $\mathrm{a}$ & 0.0 & $\mathrm{a}$ & 0.0 & $\mathrm{a}$ \\
\hline \multirow[t]{3}{*}{$2000-6922^{\dagger \dagger}$} & Joven & 81.8 & $\mathrm{a}$ & 100.0 & $\mathrm{a}$ & 0.0 & $\mathrm{a}$ & 0.0 & $\mathrm{a}$ \\
\hline & Inmadura & 0.0 & $\mathrm{~b}$ & 86.3 & $\mathrm{a}$ & 9.1 & $\mathrm{a}$ & 0.0 & $\mathrm{a}$ \\
\hline & Madura & 90.9 & $\mathrm{a}$ & 100.0 & $\mathrm{a}$ & 0.0 & $\mathrm{a}$ & 0.0 & $\mathrm{a}$ \\
\hline \multirow[t]{3}{*}{$2000-1018^{\dagger \dagger}$} & Joven & 100.0 & a & 100.0 & $\mathrm{a}$ & 0.0 & $\mathrm{a}$ & 0.0 & $\mathrm{a}$ \\
\hline & Inmadura & 18.2 & $\mathrm{~b}$ & 95.4 & $\mathrm{a}$ & 9.1 & $\mathrm{a}$ & 0.0 & $\mathrm{a}$ \\
\hline & Madura & 100.0 & $\mathrm{a}$ & 100.0 & $\mathrm{a}$ & 0.0 & $\mathrm{~b}$ & 0.0 & $\mathrm{a}$ \\
\hline \multirow{3}{*}{$97-10$} & Joven & 54.5 & $a b$ & 52.2 & $\mathrm{~b}$ & 36.3 & $a b$ & 0.0 & $\mathrm{a}$ \\
\hline & Inmadura & 18.2 & $\mathrm{~b}$ & 93.1 & $\mathrm{a}$ & 72.7 & $\mathrm{a}$ & 18.1 & $\mathrm{a}$ \\
\hline & Madura & 100.0 & $\mathrm{a}$ & 100.0 & $\mathrm{a}$ & 0.0 & $\mathrm{~b}$ & 0.0 & $\mathrm{~b}$ \\
\hline \multirow[t]{3}{*}{$97-18$} & Joven & 100.0 & $\mathrm{a}$ & 100.0 & $\mathrm{a}$ & 0.0 & $\mathrm{~b}$ & 0.0 & $\mathrm{~b}$ \\
\hline & Inmadura & 0.0 & $\mathrm{~b}$ & 61.3 & $\mathrm{~b}$ & 81.8 & $\mathrm{a}$ & 72.7 & $\mathrm{a}$ \\
\hline & Madura & 100.0 & $\mathrm{a}$ & 100.0 & $\mathrm{a}$ & 0.0 & $\mathrm{~b}$ & 0.0 & $\mathrm{~b}$ \\
\hline \multirow[t]{3}{*}{$95-8$} & Joven & 0.0 & $\mathrm{~b}$ & 45.4 & $\mathrm{~b}$ & 63.6 & $\mathrm{a}$ & 63.6 & $\mathrm{a}$ \\
\hline & Inmadura & 0.0 & $\mathrm{~b}$ & 86.3 & $\mathrm{a}$ & 81.8 & $\mathrm{a}$ & 72.7 & $\mathrm{a}$ \\
\hline & Madura & 100.0 & $\mathrm{a}$ & 100.0 & $\mathrm{a}$ & 0.0 & $\mathrm{a}$ & 0.0 & $\mathrm{a}$ \\
\hline \multirow[t]{3}{*}{$00-28$} & Joven & 100.0 & $\mathrm{a}$ & 100.0 & $\mathrm{a}$ & 0.0 & $\mathrm{a}$ & 0.0 & $\mathrm{a}$ \\
\hline & Inmadura & 36.4 & $\mathrm{~b}$ & 100.0 & $\mathrm{a}$ & 0.0 & $\mathrm{a}$ & 0.0 & $\mathrm{a}$ \\
\hline & Madura & 100.0 & $\mathrm{a}$ & 100.0 & $\mathrm{a}$ & 0.0 & $\mathrm{~b}$ & 0.0 & $\mathrm{~b}$ \\
\hline \multirow[t]{3}{*}{$97-15$} & Joven & 45.4 & $a b$ & 77.2 & $\mathrm{a}$ & 18.1 & $\mathrm{~b}$ & 0.0 & $\mathrm{~b}$ \\
\hline & Inmadura & 36.4 & $\mathrm{~b}$ & 61.3 & $\mathrm{a}$ & 72.7 & $\mathrm{a}$ & 45.4 & $\mathrm{a}$ \\
\hline & Madura & 100.0 & $\mathrm{a}$ & 100.0 & $\mathrm{a}$ & 0.0 & $\mathrm{~b}$ & 0.0 & $\mathrm{a}$ \\
\hline \multirow[t]{3}{*}{$97-20$} & Joven & 0.0 & $\mathrm{~b}$ & 22.7 & $\mathrm{~b}$ & 100.0 & $\mathrm{a}$ & 45.4 & $\mathrm{a}$ \\
\hline & Inmadura & 9.1 & $\mathrm{~b}$ & 13.6 & $\mathrm{~b}$ & 90.9 & $\mathrm{a}$ & 36.3 & $\mathrm{a}$ \\
\hline & Madura & 100.0 & $\mathrm{a}$ & 100.0 & $\mathrm{a}$ & 0.0 & $\mathrm{~b}$ & 0.0 & $\mathrm{a}$ \\
\hline \multirow[t]{3}{*}{$00-24$} & Joven & 100.0 & $\mathrm{a}$ & 100.0 & $\mathrm{a}$ & 0.0 & $\mathrm{~b}$ & 0.0 & $\mathrm{a}$ \\
\hline & Inmadura & 0.0 & $\mathrm{~b}$ & 2.2 & $\mathrm{~b}$ & 100.0 & $\mathrm{a}$ & 36.3 & $\mathrm{a}$ \\
\hline & Madura & 100.0 & $\mathrm{a}$ & 100.0 & $\mathrm{a}$ & 0.0 & $\mathrm{~b}$ & 0.0 & $\mathrm{~b}$ \\
\hline \multirow[t]{2}{*}{$95-9$} & Joven & 100.0 & $\mathrm{a}$ & 100.0 & $\mathrm{a}$ & 0.0 & $\mathrm{~b}$ & 0.0 & $\mathrm{~b}$ \\
\hline & Inmadura & 36.4 & $\mathrm{~b}$ & 18.2 & $\mathrm{~b}$ & 63.6 & $\mathrm{a}$ & 54.5 & $\mathrm{a}$ \\
\hline
\end{tabular}

Promedios $(\mathrm{n}=11)$ con la misma letra por genotipo y variable no son diferentes significativamente (Tukey, 0.01$)$.

${ }^{\dagger}$ Genotipos élite de C. arabica (el resto de los genotipos corresponden a C. canephora). 
Cuadro 2. Porcentajes de explantes con crecimiento y formación de callo de 13 genotipos élite de Coffea spp., después de $60 \mathrm{~d}$ del establecimiento in vitro.

\begin{tabular}{lcc}
\hline Genotipo INIFAP & Crecimiento (\%) & Callogénesis $(\%)^{\dagger}$ \\
\hline $95-8$ & $98.0 \mathrm{a}$ & $97.8 \mathrm{a}$ \\
$00-28$ & $93.3 \mathrm{a}$ & $93.3 \mathrm{a}$ \\
$97-20$ & $84.4 \mathrm{ab}$ & $47.8 \mathrm{bcd}$ \\
$97-18$ & $84.4 \mathrm{ab}$ & $63.3 \mathrm{~b}$ \\
$97-19$ & $68.9 \mathrm{bc}$ & $60.0 \mathrm{~b}$ \\
$97-15$ & $68.9 \mathrm{bc}$ & $56.7 \mathrm{bc}$ \\
$97-12$ & $64.4 \mathrm{bc}$ & $52.2 \mathrm{bcd}$ \\
$2000-692^{\dagger \dagger}$ & $52.2 \mathrm{~cd}$ & $51.1 \mathrm{bcd}$ \\
$95-9$ & $48.9 \mathrm{~cd}$ & $48.9 \mathrm{bcd}$ \\
$00-24$ & $37.8 \mathrm{de}$ & $30.0 \mathrm{de}$ \\
$97-10$ & $34.4 \mathrm{de}$ & $32.2 \mathrm{~cd}$ \\
$2000-1128^{\dagger \dagger}$ & $30.0 \mathrm{de}$ & $27.8 \mathrm{de}$ \\
$2000-1018^{\dagger \dagger}$ & $22.2 \mathrm{e}$ & $5.5 \mathrm{e}$ \\
\hline
\end{tabular}

${ }_{\dagger}$ Promedios con letras iguales por columna no son estadísticamente diferentes (Tukey, 0.01).

${ }^{\dagger}$ Genotipos élite de $C$. arabica (el resto corresponde a $C$. canephora).

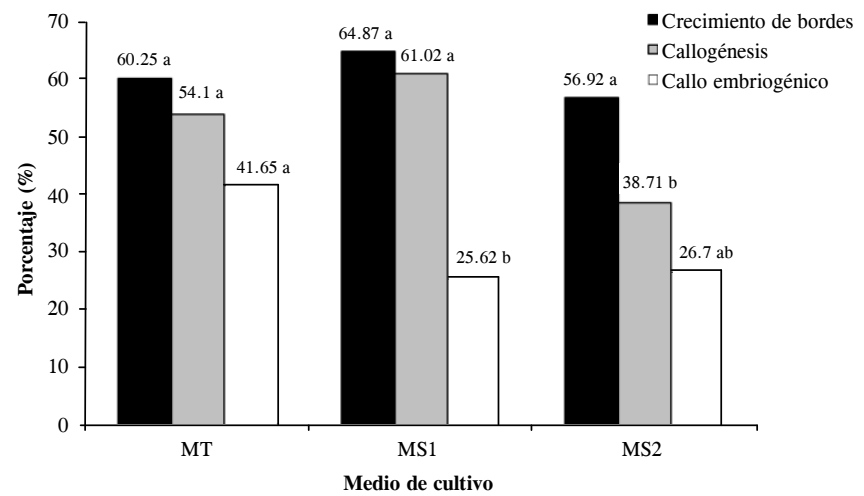

Figura 1. Porcentaje promedio de crecimiento, formación de callo y callo embriogénico de 13 genotipos élite de Coffea spp., en los tres medios de cultivo después de $60 \mathrm{~d}$ del establecimiento in vitro. MT: Yasuda-BAP; MS1: MS-BAP-2, 4-D; MS2: MS (50\%)-2,4D-AIBBAP-Benomyl. Promedios con letras iguales por medio de cultivo no son estadísticamente diferentes (Tukey, 0.01).

Entre tipos de explante de hoja se registraron diferencias $(\mathrm{P} \leq 0.01)$ en crecimiento del borde y callogénesis, pero no en formación de callo embriogénico. Los explantes provenientes de hoja inmadura presentaron los porcentajes más altos de crecimiento de bordes, callogénesis y callo embriogénico con 74, 64 y $46 \%$ respectivamente (Figura 2). Estos resultados confirman los obtenidos del experimento anterior, y estos valores se consideran altos en respuesta morfogénica.

Un factor que pudo haber influido en la baja respuesta de los explantes establecidos en el medio MS2, es la presencia del fungicida Benomyl (Figura 3a), ya que puede afectar la composición del medio de cultivo y puede llegar a ser metabolizado por el explante (Torres et al., 1998). Además, la presencia de auxinas en el medio de cultivo puede inhibir la embriogénesis somática en
Coffea, según De los Santos-Briones y HernándezSotomayor (2006).

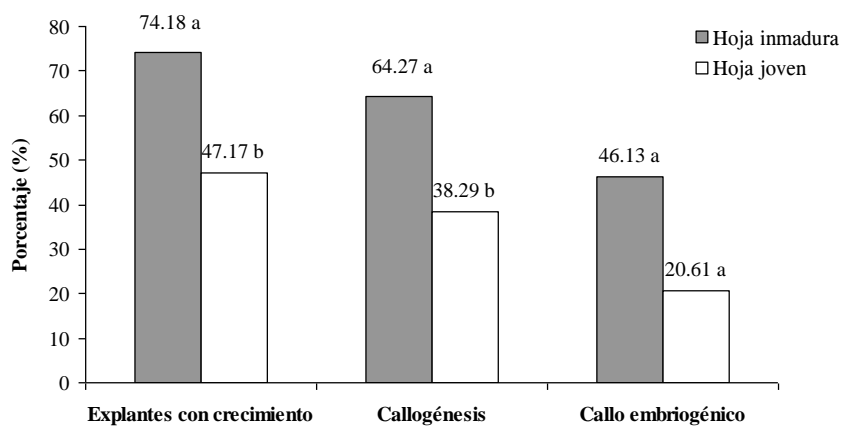

Figura 2. Porcentajes de explantes proveniente de hoja inmadura y de hoja joven con crecimiento, formación de callo y callo embriogénico de 13 genotipos élite de Coffea spp., después de $60 \mathrm{~d}$ del establecimiento in vitro. Promedios con letras iguales por variable no son estadísticamente diferentes (Tukey, 0.01 ).

En callogénesis también se detectaron diferencias significativas $(\mathrm{P} \leq 0.01)$ entre tratamientos, con excepción de los genotipos INIFAP 00-24, 00-28, 95-8 y 20001018. En los genotipos INIFAP 00-28 y 95-8 la callogénesis varió de 85 a $100 \%$, en tanto que en los otros dos genotipos no fue mayor a $55 \%$ (Cuadro 3). Los tratamientos en los cuales se usaron hojas inmaduras cultivadas en los medios MT y MS1, fueron los mejores para los genotipos INIFAP 95-9, 97-10 y 2000-1128, con callogénesis entre 53 a $100 \%$. Los genotipos INIFAP 97$15,97-19,97-18$ y 97-20 tuvieron de 40 a $60 \%$ de callogénesis, en al menos cuatro tratamientos; en el genotipo INIFAP 97-15 este valor correspondió al tratamiento de hoja joven en el medio MS2, y para el INIFAP 97-19 fue el de hoja joven en medio MS1. En el genotipo INIFAP 97-18 la mejor inducción de callogénesis se logró en tratamientos con explantes provenientes de hoja joven y hoja inmadura establecidos en los medios MT y MS1, respectivamente. Para el genotipo INIFAP 97-20 la mejor callogénesis fue en explantes provenientes de hoja joven, en cualquiera de los tres medios de cultivo. Los genotipos INIFAP 97-12 y 2000-692 presentaron su mejor respuesta en los tratamientos con explantes de hoja inmadura en los medios MT y MS1, con 85 a $100 \%$ de callogénesis, así como en hoja joven en el medio MS2 (86 \%) y hoja joven en el medio MS1 (93\%), respectivamente; en ambos genotipos se identificaron al menos tres tratamientos superiores al testigo. Con estos resultados se corrobora la marcada influencia de los componentes químicos del medio de cultivo (sales y reguladores del crecimiento), y las diferentes respuestas del material cultivado in vitro en la respuesta morfogénica, como antes indicaron Berthouly y Michaux-Ferriere (1996). 
Cuadro 3. Porcentajes de callogénesis de 13 genotipos élite de Coffea spp., establecidos en tres medios de cultivo y dos tipos de explantes a los $60 \mathrm{~d}$ del establecimiento in vitro

\begin{tabular}{|c|c|c|c|c|c|c|c|c|c|c|c|c|c|c|}
\hline \multirow{2}{*}{$\begin{array}{l}\text { Tipo de } \\
\text { hoja }\end{array}$} & \multirow{2}{*}{$\begin{array}{c}\text { Medio }^{\dagger} \\
\text { de cultivo }\end{array}$} & \multicolumn{13}{|c|}{ Genotipo INIFAP (Callogénesis \%) ${ }^{\dagger \dagger}$} \\
\hline & & $97-15$ & $97-19$ & $97-12$ & $00-28$ & $95-8$ & $95-9$ & $2000-1128^{4}$ & $2000-692^{4}$ & $2000-1018^{4}$ & $97-10$ & $97-18$ & $97-20$ & $00-24$ \\
\hline \multirow[t]{3}{*}{ Inmadura } & MT & $93.3 \mathrm{a}$ & $100.0 \mathrm{a}$ & $100.0 \mathrm{a}$ & $86.7 \mathrm{a}$ & $100.0 \mathrm{a}$ & $100.0 \mathrm{a}$ & $53.3 \mathrm{ab}$ & $100.0 \mathrm{a}$ & $13.3 \mathrm{a}$ & $100.0 \mathrm{a}$ & $86.7 \mathrm{ab}$ & $26.7 \mathrm{~b}$ & $53.3 \mathrm{a}$ \\
\hline & MS1 & $100.0 \mathrm{a}$ & $93.3 \mathrm{a}$ & $86.7 \mathrm{a}$ & $86.7 \mathrm{a}$ & $100.0 \mathrm{a}$ & $100.0 \mathrm{a}$ & $80.0 \mathrm{a}$ & $93.3 \mathrm{a}$ & $0.0 \mathrm{a}$ & $86.7 \mathrm{a}$ & $100.0 \mathrm{a}$ & $66.7 \mathrm{ab}$ & $40.0 \mathrm{a}$ \\
\hline & MS2 & $73.3 \mathrm{a}$ & $80.0 \mathrm{a}$ & $26.7 \mathrm{~b}$ & $100.0 \mathrm{a}$ & $86.7 \mathrm{a}$ & $53.3 \mathrm{~b}$ & $0.0 \mathrm{c}$ & $0.0 \mathrm{~b}$ & $0.0 \mathrm{a}$ & $6.7 \mathrm{~b}$ & $13.3 \mathrm{c}$ & $13.3 \mathrm{~b}$ & $6.7 \mathrm{a}$ \\
\hline \multirow[t]{3}{*}{ Joven } & MT & $0.0 \mathrm{~b}$ & $0.0 \mathrm{c}$ & $0.0 \mathrm{~b}$ & $100.0 \mathrm{a}$ & $100.0 \mathrm{a}$ & $13.3 \mathrm{~b}$ & $33.3 \mathrm{bc}$ & $6.7 \mathrm{~b}$ & $0.0 \mathrm{a}$ & $0.0 \mathrm{~b}$ & $60.0 \mathrm{abc}$ & $46.7 \mathrm{ab}$ & $33.3 \mathrm{a}$ \\
\hline & MS1 & $0.0 \mathrm{~b}$ & $60.0 \mathrm{ab}$ & $13.3 \mathrm{~b}$ & $86.7 \mathrm{a}$ & $100.0 \mathrm{a}$ & $13.3 \mathrm{~b}$ & $0.0 \mathrm{c}$ & $93.3 \mathrm{a}$ & $6.7 \mathrm{a}$ & $0.0 \mathrm{~b}$ & $80.0 \mathrm{ab}$ & $93.3 \mathrm{a}$ & $6.7 \mathrm{a}$ \\
\hline & MS2 & $73.3 \mathrm{a}$ & $26.7 \mathrm{bc}$ & $86.7 \mathrm{a}$ & $100.0 \mathrm{a}$ & $100.0 \mathrm{a}$ & $13.3 \mathrm{~b}$ & $0.0 \mathrm{c}$ & $13.3 \mathrm{~b}$ & $13.3 \mathrm{a}$ & $0.0 \mathrm{~b}$ & $40.0 \mathrm{bc}$ & $40.0 \mathrm{ad}$ & $40.0 \mathrm{a}$ \\
\hline
\end{tabular}

$\mathrm{MT}=$ Yasuda+BAP; MS1 = MS+BAP+2, 4-D; MS2 = MS (50\%)+2, 4-D+AIB+BAP+Benomyl

${ }^{\dagger}$ Promedios $(\mathrm{n}=15)$ con letras iguales en una columna, no son estadísticamente diferentes (Tukey, 0.01).

` Genotipos élite de C. arabica (el resto de los genotipos corresponde a C. canephora).

Cuadro 4. Medio de cultivo por genotipo para la inducción de la embriogénesis a los $60 \mathrm{~d}$ del establecimiento in vitro.

\begin{tabular}{|c|c|c|c|c|c|c|c|c|c|c|c|c|c|c|c|}
\hline \multirow{2}{*}{ Tipo de } & \multirow{2}{*}{$\begin{array}{l}\text { Medio }^{\dagger} \text { de } \\
\text { cultivo }\end{array}$} & \multicolumn{14}{|c|}{ 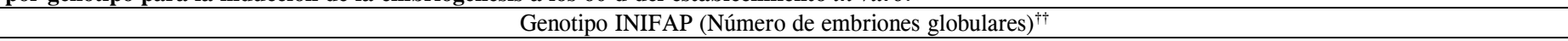 } \\
\hline & & $97-15$ & $97-19$ & $97-12$ & $00-28$ & $95-8$ & $95-9$ & $2000-1128^{4}$ & $2000-692^{4}$ & $2000-1018^{4}$ & $97-10$ & $97-18$ & $97-20$ & $00-24$ & $\begin{array}{c}\text { Promedio } \\
\text { medio } \xi \xi\end{array}$ \\
\hline \multirow[t]{4}{*}{ Inmadura } & MT & 60 & 863 & 127 & 486 & 48 & 309 & 208 & 312 & 539 & 1245 & 66 & 116 & 809 & 406 a \\
\hline & MS1 & 0 & 0 & 0 & 608 & 80 & 0 & 48 & 23 & 0 & 365 & 0 & 521 & 232 & $144 \mathrm{~b}$ \\
\hline & MS2 & 359 & 193 & 361 & 294 & 190 & 93 & 0 & 0 & 0 & 0 & 225 & 452 & 0 & $166 a b$ \\
\hline & Promedio $^{\text {If }}$ & $140 \mathrm{a}$ & 352 a & $173 \mathrm{a}$ & $463 a$ & 106 a & $133 \mathrm{a}$ & 86 a & 112 a & $180 \mathrm{a}$ & 536 a & $97 \mathbf{a}$ & 385 a & 347 a & \\
\hline \multirow[t]{4}{*}{ Joven } & MT & 0 & 0 & 0 & 597 & 705 & 592 & 90 & 0 & 0 & 0 & 258 & 581 & 474 & 253 a \\
\hline & MS1 & 0 & 341 & 0 & 0 & 294 & 415 & 0 & 361 & 0 & 0 & 0 & 0 & 0 & 108 a \\
\hline & MS2 & 311 & 415 & 511 & 77 & 119 & 0 & 0 & 415 & 353 & 0 & 269 & 808 & 452 & $287 \mathrm{a}$ \\
\hline & Promedio $^{\text {q }}$ & $103 \mathrm{a}$ & 252 a & $170 \mathrm{a}$ & $225 \mathrm{a}$ & $373 \mathrm{a}$ & 336 a & 30 & 258 a & 118 a & $\mathbf{0}$ a & 175 a & $463 \mathrm{a}$ & 309 a & \\
\hline \multicolumn{2}{|c|}{ Promedio/genotipo } & $121 \mathrm{a}$ & $302 \mathrm{a}$ & $172 \mathrm{a}$ & $344 \mathrm{a}$ & $239 \mathrm{a}$ & $234 \mathrm{a}$ & $58 \mathrm{a}$ & $185 \mathrm{a}$ & $149 \mathrm{a}$ & $268 \mathrm{a}$ & $136 \mathrm{a}$ & $424 \mathrm{a}$ & $328 \mathrm{a}$ & \\
\hline
\end{tabular}

${ }^{\dagger} \mathrm{MT}=$ Yasuda+BAP; MS1 = MS+BAP+2, 4-D; MS2 = MS (50\%)+2, 4-D+AIB+BAP+Benomyl.

${ }^{\dagger}$ Número de embriones globulares en una muestra de $0.83 \mathrm{~g}$ de callo.

'Genotipos élite de C. arabica (resto de los genotipos corresponden a C. canephora).

"Promedios con letras iguales en la fila, entre genotipos, para cada tipo de hoja no son diferentes estadísticamente (Tukey, 0.05).

${ }^{\xi}$ Promedios con letras iguales en la fila, entre genotipos, no son diferentes estadísticamente (Tukey, 0.05).

${ }_{\xi}^{\xi}$ Promedios con letras iguales en la columna, entre medios de cultivo, no son diferentes estadísticamente (Tukey, 0.05). 
En la muestra de $0.83 \mathrm{~g}$ de callo no se detectaron diferencias entre tratamientos en el número de embriones (Cuadro 4). Nótese que porcentajes altos de callogénesis no siempre condujeron a la formación de embriones (Figura 3b); por ejemplo, las hojas inmaduras del genotipo INIFAP 97-15 cultivadas en el medio MS1 respondieron favorablemente a la formación de callo (100 $\%)$, pero no formaron embriones. En contraparte, las hojas jóvenes del genotipo INIFAP 2000-692 cultivadas en el medio (MS2) tuvo $13 \%$ de callogénesis y 415 embriones en estado globular en $0.83 \mathrm{~g}$ de callo (Figura 3c y 3d). Además los explantes de hojas inmaduras y jóvenes del genotipo INIFAP 00-28 produjeron una alta proporción de embriones somáticos, sin pasar por la fase de callo (Figura 3e y $3 \mathrm{f}$ ).

Lo anterior indica que la capacidad de formación de callo no siempre conduce a la capacidad de formación de embriones somáticos. También se aprecia que es posible inducir embriogénesis somática a partir de los dos tipos de explantes foliares, jóvenes e inmaduras, en los que siempre hubo respuesta a al menos uno de los tres medios de cultivo.

\section{CONCLUSIONES}

Los explantes provenientes de hoja inmadura y de hoja joven de Coffea spp., presentaron mejor capacidad de respuesta morfogénica que los de hoja madura, en cuanto a la inducción de callo. Esta inducción de callo también varió entre genotipos, y el callo generado no siempre fue embriogénico. Se logró inducir embriogénesis somática tanto en hojas jóvenes como en hojas inmaduras, en al menos uno de los tratamientos, lo que permitió identificar un tipo de explante y medio de cultivo óptimo por cada genotipo, lo que contribuirá a hacer más eficiente la multiplicación masiva de Coffea spp.

\section{AGRADECIMIENTOS}

A los Fondos Sectoriales SAGARPA-CONACYTCOFUPRO-2004-C01-116 y a la empresa NESTLÉ S.A. de C.V., por el financiamiento otorgado para este trabajo de investigación.

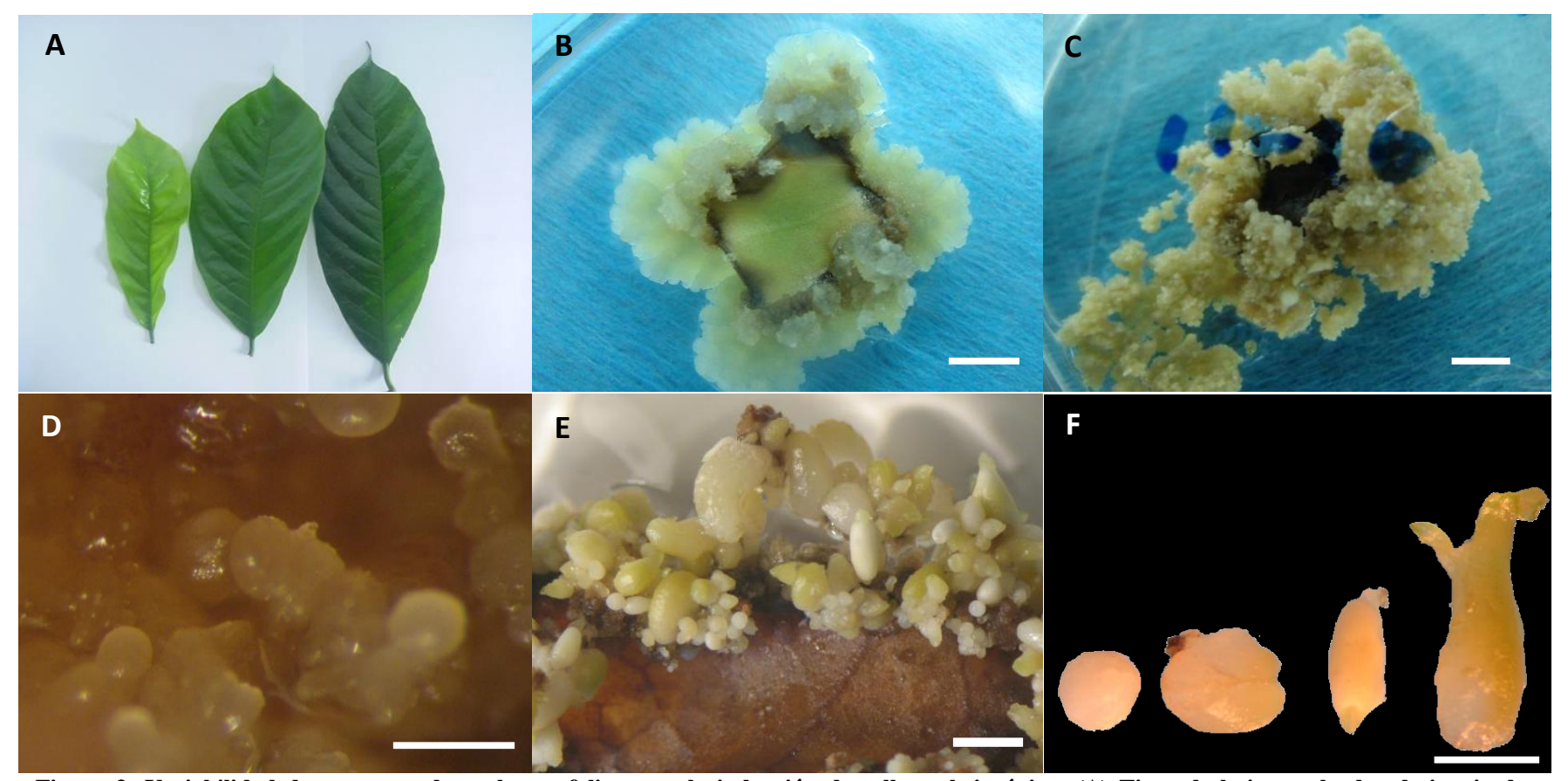

Figura 3. Variabilidad de respuesta de explantes foliares en la inducción de callo embriogénico: (A) Tipos de hoja empleadas de izquierda a derecha: hoja inmadura, hoja joven y hoja madura. (B) Explante de hoja inmadura con alta producción de callo no embriogénico, barra $=5$ $\mathrm{mm}$. (C) Explante de hoja inmadura con alta producción de callo embriogénico, barra $=5 \mathrm{~mm}$. (D) Acercamiento de callo embriogénico, donde se observan embriones globulares, barra $=2 \mathrm{~mm}$. (E) Embriogénesis somática directa en el genotipo INIFAP 00-28, barra $=1 \mathrm{~mm}$. (F) Estados de desarrollo de embriones somáticos de café del genotipo INIFAP 00-28, barra $=1 \mathrm{~mm}$. 


\section{BIBLIOGRAFÍA}

Afreen F, S M A Zobayed, T Kozai (2002) Photoautotrophic culture of Coffea arabusta somatic embryos: photosynthetic ability and growth of different stage embryos. Ann. Bot. 90:11-19.

Aftab F, J Iqbal (1999) Plant regeneration from protoplasts derived from cell suspension of adventive somatic embryos in sugarcane (Saccharum spp. hybrid cv. CoL-54 and cv. CP-43/33). Plant Cell Tiss. Org. Cult. 56:155-162.

Berthouly M, N M Michaux-Ferriere (1996) High frequency somatic embryogenesis in Coffea canephora. Induction conditions and histological evolution. Plant Cell Tiss. Org. Cult. 44:169-176.

Boxtel J V, M Berthouly (1996) High frecuency somatic embryogenesis from coffee leaves. Plant Cell Tiss. Org. Cult. 44:7-17.

Cueto J, J F Aguirre-Medina, L Iracheta-Donjuan, A ZamarripaColmenero, A Olivera-De los Santos, M Grajales-Solís (2007) Propagación. In: El Mejoramiento del Cultivo de Cacao (Theobroma cacao L.) en México. Instituto Nacional de Investigaciones Forestales, Agrícolas y Pecuarias. Campo Experimental Rosario Izapa. Tuxtla Chico, Chiapas, México. Libro técnico. pp:103-132.

De los Santos-Briones C, T Hernández-Sotomayor (2006) Coffe biotechnology. Minireview Braz. J. Plant Physiol. 18:217-227.

Dublin P (1981) Embryogenese somatique directe sur fragments de feuilles de caféier arabust. Café Cacao Thé 25:237-242.

Ducos J P, A Zamarripa, Eskés, V Pétiard (1993) Production of somatic embryos of Coffee in a bioreactor. In : Association Scientifique Internationale du Café (ed) $15^{\circ}$ Int. Sci. Colloquium Coffee. Paris. pp:89-96.

Ducos J P, M Gianforcaro, B Florin, V Pétiard, A Deshayes (1999) A technically and economically attractive way to propagate elite Coffea canephora (Robusta) clones: in vitro somatic embryogenesis. In: XVIII Colloquium Sci. Int. Coffee. Helsinki. pp:295-301.

Gamborg O L (2002) Plant Tissue Culture. The Technology. Part 1. Exegetics Ltd. Edington. $547 \mathrm{p}$.

George E (1996) Plant propagation by tissue culture. Part 2. In Practice. 2nd ed. Exegetics Ltd. England. 1361 p.

Giridhar P, V Kumar, E P Indu, G A Ravishankar, A Chandrasekar (2004) Thidiazuron induced somatic embryogenesis in Coffea arabica L. and C. canephora P. ex Fr. Acta Bot. Croat. 63:25-33.

González M E, N Santana, C López (2001) Efecto de la composición del medio de cultivo y el genotipo en la inducción de la embriogénesis somática en clones de Coffea canephora P., var., Robusta. Cult. Trop. 22:17-21.

González O S, J J Silva, A Espinoza, C Ros, L Acosta, S Meneses, M M Hernández (2002) La embriogénesis somática en Ipomoea : Una posibilidad para la multiplicación y conservación de los recursos vegetales. Cuad. Biodiversidad 4:15-21.

Hartmann H T, D E Kester (1998) Techniques of in vitro culture of micropropagation. In: Plant Regeneration Principles and Practices. $6^{\text {th }}$ ed. H. Hartmann T, D Kester (eds). Prentice Hall. New Jersey, USA. pp:549-608.

Herman E B, G J Haas (1975) Clonal propagation of Coffea arabica L. from callus culture. HortScience 10:588-589.

İpekçi Z, N Gözz̈kirmizi (2003) Direct somatic embryogenesis and synthetic seed production from Paulownia elongata. Plant Cell Rep. 22:16-24.
Jha S, S Das (2004) Tissue culture of cashewnut. In: Plant Biotechnology and Molecular Markers. P Srivastava, A Narula, S Srivastava, S Anamaya (publs). New Delhi, India. pp:244260.

Jensen P J, R P Hangarter, M Estelle (1998) Auxin transport is required for hypocotyl in ligth-grown but not dark-grown Arabidopsis. Plant Physiol. 116:455-462.

Lallana M C, C E Billard, J H Elizalde, V H Lallana (2006) Breve revisión sobre características de la cutícula vegetal y penetración de herbicidas. Ciencia, Docencia y Tecnología 33:229-241.

Lanaud C (1981) Production de plantules de C. canephora par embryogenèse somatique réalisée à partir de culture in vitro d'ovules. Café Cacao Thé 25:231-236.

Margara J (1988) Multiplicación vegetativa y cultivo in vitro; los meristemos y la organogénesis. Ed. Mundi Prensa. Madrid, España. pp:171-197.

Mittler L, S Vanderauwera, M Gollery, F Breusegem (2004) Reactive oxygen gene network of plants. Trends Plant Sci. 9:490-498.

Murashige T, F Skoog (1962) A revised medium for rapid growth and bioassays with tobacco tissue cultures. Physiol. Plant. 15:473497.

Naidu M M, H L Sreenath (1998) In vitro culture of coffee zygotic embryos for germplasm preservation. Plant Cell Tiss. Org. Cult. 55:227-230.

Nguyen Q T, T Kozai, U V Nguyen (1999) Effects of sucrose concentration, supporting material and number o fair exchanges of the vessel on the growth of in vitro coffee plantlets. Plant Cell Tiss. Org. Cult. 58:51-57.

Pido N, Y Kowyama, K Shimonishi, M Karube (1995) Plant regeneration from adventitious root segments derived from leaf disk of sweet potato cultivar jewel. Plant Tiss. Cult. Biotech. 1:81-84.

Sánchez-Cuevas M C, J L Salaverría (2004) Control de la oxidación y la contaminación en el cultivo in vitro de fresa (Fragaria $\mathrm{x}$ ananassa Duch.). UDO Agrícola 4:21-26.

Sondahl M R and W R Sharpe (1977) High frecuency induction of somatic embryos in cultured leaf explants of Coffea arabica $\mathrm{L}$. Z. Planzenphysiol. 81:395-408

Staritsky G (1970) Embryo formation in callus tissues of coffee. Acta Bot. Neerlandica 19:509-514.

Torres A C, L A Caldas, J A Buso (1998) Cultura de Tecidos e Transformacao Genética de Plantas. Vol. 1. Embrapa. Brasil. $509 \mathrm{p}$.

Velázquez M, A González, F Mata, S León de Sierralta, D Esparza, M Ramírez (2004) Tipo de sombreamiento y tiempo de crecimiento de brotes laterales sobre la viabilidad de explantes de Annona muricata L. Rev. Fac. Agron. Luz 21:12-18.

Yasuda T, Y Fujii, T Yamaguchi (1985) Embryogenic callus induction from Coffea arabica leaf explants by benzyladenine. Plant Cell Physiol. 26:595-597.

Zamarripa C A (1994) Optimización de la embriogénesis somática del café Arabusta (Coffea canephora P. x Coffea arabica L.) a partir de una suspensión celular. Agric. Téc. Méx. 20:27-41.

Zamarripa C A, V Pétiard (2004) Biotechnologies applied to coffee. In: Coffee: Growing, Process, Sustainable Production. J N Wintgens (ed). Wiley-VCH Verlag Gmbtl and Co. KGaA. pp:137-163.

Zhong L, D Shihua, K Jin, L Shaoqing, L Yangsheng, Z Yingguo (2007) A sigle genetic locus in chromosome 1 controls conditional browning during the induction of calli from mature seeds of Oryza sativa spp. indica. Plant Cell Tiss. Org. Cult. 89:273-245. 